\section{Epilepsy related to traumatic extradural haematomas}

\author{
A B Jamjoom, N Kane, D Sandeman, \\ B Cummins
}

Department of

Neurosurgery, Frenchay

Hospital, Bristol BS16 1LE

A B Jamjoom, FRCSED(SN),

registrar

N Kane, MB, senior house

officer

D Sandeman, FRCS, senior

house officer

B Cummins, FRCS, consultant

neurosurgeon

Correspondence to:

Mr A B Jamjoom,

Department of

Neurosurgery, King Khalid

University Hospital,

PO Box 2925, Riyadh 11461,

Saudi Arabia.

BMF 1991;302:448 tomography.

\section{Patients, methods, and results}

Intracranial haematoma is a well recognised risk factor for post traumatic epilepsy, whether early or late.' Epilepsy occurs more commonly after an intradural rather than extradural haematoma. ${ }^{1}$ Studies published before computed tomography became available report incidences of epilepsy after traumatic extradural haematoma of $22 \%$ and $0-29 \% .^{12}$ Concomitant intradural damage, which probably influences the development of epilepsy, could not then have been assessed. We studied the incidence of epilepsy in patients who required surgery for traumatic extradural haematoma with reference to the results of preoperative computed

We conducted a retrospective analysis of 138 patients treated for traumatic extradural haematoma at this hospital between 1975 and 1987. Forty three patients were eliminated from the study: 18 had no preoperative scan, 15 died within two weeks after the injury, and 10 were lost to follow up. For the remaining 95 patients we reviewed the hospital records and preoperative computed tomograms. Follow up was achieved with the hospital notes and by sending questionnaires to the patients and their general practitioners. The patients were categorised according to the findings on computed tomography. Sixty six patients had an extradural haematoma with no evidence of intradural damage (group A). Twenty nine patients had an intradural abnormality in addition to the extradural haematoma (group B), the lesions being a subdural haematoma in five, a haemorrhagic contusion in 16, and hemisphere swelling in eight. Follow up ranged from two to 14 years (mean 8.6 years).

Epilepsy was considered to be early when the convulsion occurred within the first week after the

Clinical details of patients with traumatic extradural haematomas. Values are numbers (percentages) of patients unless stated otherwise

\begin{tabular}{lccc}
\hline & Group A & Group B \\
\cline { 2 - 2 } & $\begin{array}{c}\text { Extradural } \\
\text { haematoma alone }\end{array}$ & $\begin{array}{c}\text { Extradural } \\
\text { haematoma and } \\
\text { intradural damage }\end{array}$ \\
\hline No of patients & 66 & & 29 \\
Age range (mean) (years) & $1-56(23 \cdot 3)$ & & $11-74(34 \cdot 6)$ \\
Fracture: & $49(74)$ & & $22(76)$ \\
$\quad$ Linear & $1(2)$ & & $4(14)$ \\
Depressed & $11(17)$ & & $18(62)$ \\
Prophylactic anticonvulsants & $3(5)$ & & $6(21)$ \\
Epilepsy: & $1(2)$ & & $5(17)$ \\
$\quad$ Early & $4(6)$ & $7(24)$ \\
$\quad$ Late & $9 \cdot 0$ & $7 \cdot 8$ \\
Overall & &
\end{tabular}

injury and late when it occurred after one week. The table shows the incidence of epilepsy in both groups. The difference in the overall incidence of epilepsy was significant $\quad\left(\chi^{2}=4.79\right.$ with Yates's correction; $\mathrm{p}=0.029$ ).

All of the six patients who developed late epilepsy did so within the first year. Of the nine patients with early epilepsy, four (all from group B) developed late epilepsy; the five others had not developed late epilepsy at a mean follow up of 10 years.

None of the five patients with depressed skull fracture developed epilepsy. Prophylactic anticonvulsant treatment was prescribed to a total of 29 patients. None of the 11 patients in group A developed late epilepsy compared with four of the 18 in group $B$.

\section{Comment}

All published reports group patients with traumatic extradural haematoma together and quote an overall incidence of epilepsy. To our knowledge no previous report has tried to define the incidence of epilepsy after an extradural haematoma and to compare it with that in patients with additional intradural damage. We found the overall incidence of late epilepsy to be $6 \%(6 / 95)$, but in group $\mathrm{A}$ the incidence was $2 \%$ and in group B $17 \%$, which is comparable with Jennett's value of $22 \%$. ${ }^{1}$

Interestingly, the difference in the mean age of the two groups was more than 10 years. The mean age of patients who had early and late epilepsy was, however, 22.2 years in group $A$ and 25.1 years in group $B$, which is younger than the mean age of all of the patients. Annegers $e t$ al found that children (aged $<15$ years) had a higher incidence of early post traumatic epilepsy but a significantly lower incidence of late epilepsy than adults. $^{3}$

The indication for prophylactic anticonvulsant treatment after head injury is still debatable, with obvious variation in policies among different clinicians. Prophylactic anticonvulsants were prescribed more often to patients in group B, which shows that clinicians in our unit believed that patients with extradural and intradural damage were more likely to develop epilepsy. Four of the 29 patients who had prophylactic treatment developed late epilepsy whereas only two of the 66 who did not receive it did so. Such observations do not support the role of prophylaxis against late epilepsy in traumatic extradural haematomas.

We conclude that the risk of late epilepsy after an isolated extradural haematoma is small. Additional intradural abnormality substantially increases the risk of epilepsy. The value of preoperative computed tomography in delineating both groups is crucial. The distinction is likely to produce a fairer outcome when the matter of fitness to drive is considered.

1 Jennett B. Epilepsy and acute traumatic intracranial haematoma. $f$ Neurol Neurosurg Psychiatry 1975;38:378-81.

Jennett B. Epilepsy after non-missile head injuries. 2nd ed. London: Heinemann 1975:136-43.

3 Annegers JF, Grabow JD, Groover RV, et al. Seizures after head trauma in population study. Neurology 1980;30:683-9.

Accepted 2 November 1990 